\title{
El doctor Margalef, un dels pares de l'Écologia moderna
}

\author{
Marina Mir \\ Professora jubilada de Ciències Naturals de Secundària
}

Per als estudiosos de la Vida, el Dr. Margalef no és només una figura molt important, sinó extraordinària, perquè ha contribuït a l'avenç de la Ciència d'una manera molt notable i innovadora alhora.

\section{L'Oceanografia, \\ la Limnologia i els seus treballs}

En primer lloc, va contribuir a la Ciència com a coneixedor d'allò que és propi del camp de la Biologia, de la Historia Natural. Ell es considerava, per damunt de tot, un naturalista. Encuriosit coneixedor de totes les formes de vida dels éssers vius, sentia una particular afecció per les més petites, com és el món del plàncton. Hi va dedicar molts treballs, molt precoçment, com a autodidacte. I tant en la confecció de claus de classificació, com en la invenció d'aparells per a millorar-ne la captura de mostres i el comptatge.

Era, a més de traçut amb les mans, bon dibuixant. Dominava diverses llengües i va ser pioner en les dues especialitats sobre l'aigua: l'Oceanografia i la Limnologia (aquesta, dedicada a l'estudi de les aigües continentals). Si ho hagués estat en una de sola, ja li hauria valgut el gran reconeixement científic que obtingué.

Fou el primer catedràtic d'Ecologia de l'Estat Espanyol. Malgrat les temptadores ofertes per part de països molt més avançats que el nostre en el camp científic, ell va romandre aquí i és on va treballar.

Tanmateix, Margalef era un viatger incansable. També una persona d'una gran cultura humanística: lector infatigable i escriptor d'una rara qualitat. Els seus nombrosos escrits científics -ens ha llegat més de 400 treballs publicats-, fins i tot els més difícils conceptualment, presenten sovint un estil que harmonitza l'exactitud i el rigor que exigeix la comunicació científica amb un alenar propi de la millor poesia. Hi ha una obra seva de divulgació, "Planeta azul, Planeta Verde", on això es posa particularment de manifest.

\section{Un dels pares de l'ecologia moderna}

Però el que realment singularitza Margalef en el camp científic i li dóna el prestigi internacional, és el fet que podem considerar-lo un dels pares de l'Ecologia moderna. Són ben pocs els homes de ciència als que se'ls reconeix el mèrit d'haver contribuït a crear una ciència nova, amb paradigmes propis, que contribueix a millorar el coneixement del nostre univers.

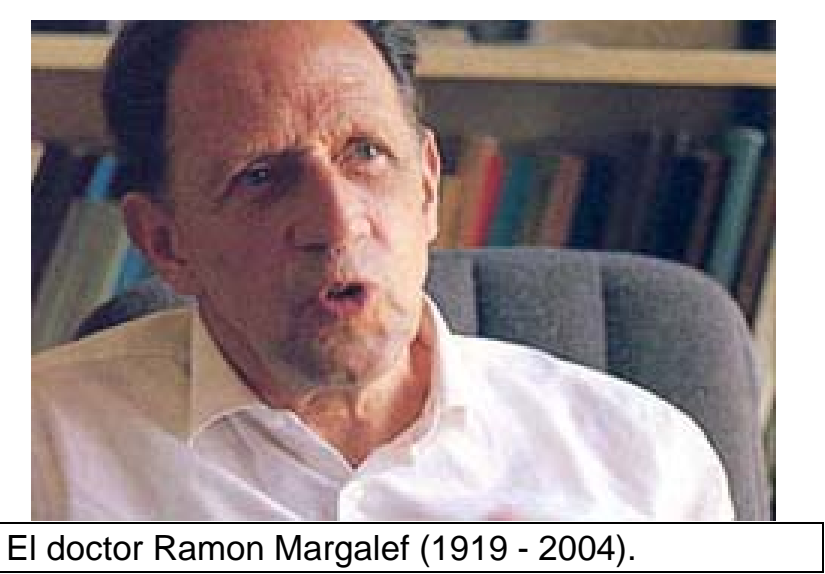

Des de l'Ecologia, la Vida es contempla com un procés evolutiu força més complex i més ric del que ho fa la Biologia tradicional. S'ha dit que "l'Ecologia estudia la biologia dels ecosistemes" i la seva evolució, com a resultat d'un ajustament constant entre la dinàmica de les poblacions i les condicions del medi físic on es troben; el mateix entorn físic que 
avui s'ha posat de moda anomenar "Medi Ambient", de manera, per cert, força desafortunada.

\section{Societat i Ecologia}

Ara bé, si l'estudi de les relacions entre les poblacions d'organismes i el seu entorn és el que constitueix la base de l'Ecologia i el seu objectiu és entendre com funciona la biosfera en el seu conjunt, hem d'admetre que ens trobem davant d'una evidència fascinant. Potser per primera vegada, $\mathrm{i}$ sens dubte com mai abans del moment actual, els humans ens trobem enfrontats amb l'evidència que la nostra població, les nostres societats, formen part d'aquest sistema de relacions.

Molts dels problemes que afecten les societats humanes, en la seva mateixa base orgànica, troben una interpretació racional, científica, en la lectura del funcionament dels sistemes naturals. Ens poden semblar aliens, però no ho són des del moment que nosaltres com a espècie en formem part $i$ que necessitem explotar-los per a viure.

Es més, des del moment que els humans adquirim consciència que aquestes relacions existeixen $i$ que obeeixen les seves pròpies lleis de funcionament, ens trobem en millors condicions d'entendre com ens afecten i també com les afectem nosaltres amb el nostre comportament.

La importància de l'Ecologia és fàcil d'admetre si entenem que ens ajuda a conèixer els processos que governen la vida al planeta i la nostra pròpia subsistència en ell. L'exemple més clar d'això el trobem en les xarxes tròfiques. Els éssers vius depenem de la producció orgànica dels vegetals 0 producció primària; i aquesta, al seu torn, de determinats factors, el primer dels quals és la disponibilitat d'aigua i de nutrients, així com de la temperatura i altres factors físics relacionats.

La fotosíntesi és la base d'una enorme diversitat de processos meravellosos, sovint sorprenents, que mantenen funcionant la maquinària de la vida gràcies a una transformació constant de l'Energia.

L'Ecologia tracta d'interpretar aquests processos, quantificar-los i trobar-hi regularitat o lleis. En la mesura que ho aconsegueix, ens revela les pautes que sostenen els recursos naturals del quals depèn el funcionament de la vida. També la de les societats humanes.

Amb aquestes premisses resulta fàcil admetre que aquests estudis ens obliguen a tenir en compte els coneixements que són propis d'altres branques de la Ciència, que tenen els seus propis paradigmes -diferents dels de la Biologia- $\mathrm{i}$ molt en particular la Física, d'acord amb el que ens mostra i demostra tota la obra escrita de Margalef.
Títols com ara "La Biosfera, entre la Termodinámica y el Juego" donen un clar testimoni d'aquesta projecció. A "Perspectivas de la teoria ecológica"-l'obra que li valgué el reconeixement internacional- relaciona la Biologia amb l'aleshores incipient Teoria de la Informació.

Per si la seva obra no fos prou meritòria, Margalef constitueix un model de científic honest, d'humanista molt complet, d'home humil, generós, rotundament bo.

\section{El científic català més important}

És per tot plegat que, en el seu cas, qualificar-lo de savi no resulta en absolut una exageració. Tal com afirma J. Terradas, un dels seus nombrosos deixebles dispersos arreu del món, "Margalef ha estat l'investigador de l'Estat Espanyol, en qualsevol branca del coneixement, que ha tingut més repercussió internacional en la segona meitat del segle XX i el científic català més important."

El doctor Margalef, tot i optant per treballar al nostre país, -tan roí en proporcionar mitjans als científics- va ser un autèntic precursor, reconegut $i$ honorat en l'àmbit internacional.

Això, no només mereix un reconeixement públic, sinó que també obliga a un esforç educatiu important que permeti rendibilitzar l'actiu dels seus mèrits, tant científics com personals.

Conèixer i estudiar la seva obra és obligat par a tothom que es consideri culte, és a dir, conscient del que ens aporten els coneixements actuals per ajudar-nos a situar i mirar d'entendre'ns dins de l'Univers.

\section{Bibliografia}

Margalef, R. (1968). Perspectives in ecological theory. University of Chicago Press.

Margalef, R. (1980). La Biosfera: entre la termodinámica y el juego. Omega: Barcelona.

Margalef, R. (1992). Planeta azul: Planeta verde. Biblioteca Scientific American, Prensa Científica: Barcelona.

Per consultar la seva obra cal adreçar-se a http://www.icm.csic.es/bio/personal/fpeters/margale f/index.htm

També hi ha informació a la web del Premi Ramon Margalef d'Ecologia i ciències Ambientals: http://www.gencat.net/premiramonmargalef/cat/ram on margalef.htm 